\title{
ERYTHROCYTE ACID PHOSPHATASE: SPECIES SPECIFICITY IN ACTIVITY MODULATION BY PURINE ANALOGS
}

\author{
J. M. NAIDU* and H. W. MOHRENWEISER \\ Department of Human Genetics, University of Michigan Medical School, Ann Arbor, MI 48109, USA
}

(Tel: 313-764-4434)

(Received 11 September 1984)

\begin{abstract}
The previous studies of the interaction of purine analogs and human erythrocyte acid phosphatase isozymes were extended to include erythrocyte acid phosphatase from seven other species.

2. Consistent responses, similar to the observations with the several genotypically different human isozymes, were observed.

3. The isozyme from chimpanzee erythrocytes was similar to the human B-type isozyme while the baboon and cow isozymes were at the other extreme in responsiveness and were more divergent from the $\mathrm{B}$-isozyme than was the human A-type isozyme. The ACP from rabbit, dog, sheep and rhesus erythrocytes exhibited intermediate levels of responsiveness but did differ from the human A-type isozyme.

4. Additional studies indicated some differences between the responsiveness of the partially purified erythrocyte enzyme and the low molecular weight ACP from liver.
\end{abstract}

The catalytic mechanism of the erythrocyte acid phosphatase (ACP; EC 3.1.3.2) involves a phosphoenzyme intermediate, with the removal of the phosphate being the rate limiting step in the reaction (Tanizuki et al., 1977; Baldijao et al., 1975; Saini et al., 1981). The rate of phosphate transfer is enhanced when $\mathrm{H}_{2} \mathrm{O}$ is replaced by a series of alcohols as the phosphate acceptor (Tanizaki et al., 1977; Yoshihara and Mohrenweiser, 1980; Luffman and Harris, 1967). The rate of phosphate transfer is also modulated by a series of purine analogs, with most of the studies involving the human erythrocyte isozymes (Mansfield and Sensabaugh, 1977, 1978; Sensabaugh and Golden, 1978; Yoshihara and Mohrenweiser, 1980; Mohrenweiser and Novotny, 1982). The extent and direction, either activation or inhibition, of the modulation of the reaction rate by these analogs is dependent upon both the substituent and more importantly, the position of the adduct, that is, the modulation, acting via an uncompetitive mechanism, exhibits specificity with regard to the structure of the purine analog (Mansfield and Sensabaugh, 1978; Wurzinger et al., 1984).

The extent (but not the direction) of the response is also sensitive to the structure of the enzyme. Previous studies have shown that the modulation of the activity of the three common allelic forms of the human enzyme by purine analogs is phenotype specific. The order of response, either activation or inhibition of the activity of the common alleles, is C:A:B (Mansfield and Sensabaugh, 1977, 1978; Sensabaugh and Golden, 1978). Other variants exhibit similar genotype specificity (Yoshihara and Mohrenweiser, 1980; Mohrenweiser and Novotny, 1982). The human ACP isozymes also differ in other characteristics, e.g. level of enzyme activity (Spencer et al.,

*Present address: Department of Anthropology, Andhra University, Waltair, India 53003.
1964; Eze et al., 1974) and thermostability (Yoshihara and Mohrenweiser, 1980, Luffman and Harris, 1971) but the ordering of these phenotype specific characteristics differ from those observed for the purine modulation.

This study of the response of the erythrocyte ACP from a series of primate and nonprimate species confirms the role of ACP structure in dictating the response to purine analog modulation. The differences in responsiveness, between species, were larger than observed for the common human isozymes but the isozyme specificity of the response was maintained.

\section{MATERIALS AND METHODS}

Blood samples were collected, washed and stored as described by Fielek and Mohrenweiser (1979). Hemolysates for electrophoresis were prepared as described by Mohrenweiser and Novotny (1982). Vertical starch gel electrophoresis was utilized to confirm the ACP phenotypes (Neel et al., 1980). Hemolysates for activity studies were prepared as described by Yoshihara and Mohrenweiser (1980).

ACP activity, with $p$-nitrophenyl phosphate ( $p$-NPP) as substrate, was assayed as described by Wurzinger et al. (1984). The incubation time was 10 minutes at $37^{\circ} \mathrm{C}$. The acquisition of the blood samples from the primate species (Papio anubis, baboon; Macaca mulatta, rhesus; Pan paniscus, chimpanzee) has been described by Turner et al. (1984). The samples from dog, Canis familiaris, sheep, Ovis aries and rabbit, Oryctolagus cuniculus were obtained from healthy animals maintained by the University of Michigan Laboratory Animal Care Unit while the bovine (Bos taurus) samples were obtained through the Department of Animal Science at Michigan Science University.

The following fractionation procedure was used for the partial purification of the low molecular weight ACP from human, bovine and rabbit liver. The tissue was homogenized with four volumes of $0.1 \mathrm{M}$ potassium phosphate buffer (pH 7.0) containing $1 \mathrm{mM}$ ethyleneglycol-bis-( $\beta$-aminoethyl ether)- $N, N, N^{1}, N^{1}$, tetraacetic acid (EGTA), $0.1 \%$ Triton $\mathrm{X}-100$ and $1 \mathrm{mM}$ 2-mercaptoethanol. The homogenates 
were centrifuged for $30 \mathrm{~min}$ at $20,000 \mathrm{~g}$. Solid ammonium sulfate was added to the supernatant to $40 \%$ saturation. The pellet was discarded and the supernatant was made $70 \%$ saturated with ammonium sulfate. The pellet was redissolved in a minimum amount of column equilibrating buffer $(0.1 \mathrm{M}$ potassium phosphate $(\mathrm{pH} 7.0), 0.1 \mathrm{M} \mathrm{KCl}$, $1 \mathrm{mM}$ EGTA, I mM 2-mercaptoethanol, and $0.01 \%$ Triton $X-100$ ). The samples were dialyzed overnight against 10,000 vol of the same buffer. One $\mathrm{ml}$ of the dialyzed sample was applied to a Sephadex G-100 column $(1.5 \times 50 \mathrm{~cm})$ (Sensabaugh, 1975). The flow rate was $5-7 \mathrm{ml} / \mathrm{hr}$. The fractions were assayed for ACP activity and the low molecular weight ACP fractions (collected after hemoglobin was eluted) were concentrated by dialysis against polyethyleneglycol $(\mathrm{MW}=20,000)$. The concentrated samples were dialyzed against $0.01 \mathrm{M}$ Tris ( $\mathrm{pH} 7.4$ ), $0.14 \mathrm{M} \mathrm{NaCl}$ buffer containing $0.1 \%$ Triton $\mathrm{X}-100$ and $7 \mathrm{mM}$ 2-mercaptoethanol. The erythrocyte ACP from each of the three species was fractionated by similar procedures. All of the samples were adjusted to the same level of ACP activity.

All assays were done in duplicate and samples from at least two individuals of each phenotype and species were used. The range of variation among individuals and/or replicates was less than 10 percentage points. The rate of product formation was linear with time for all assay conditions employed.

All purine analogs, as well as $p$-nitrophenyl phosphate, were obtained from Sigma Chem. Co. (St. Louis, MO) and used without further purification.

\section{RESULTS}

\section{Electrophoresis}

The electrophoretic mobility of the erythrocyte ACP from the several species is shown in Fig. 1. Greater separation of the isozymes is observed with the Tris-maleate buffer than with the Tris-citrate buffer. The relative pattern of the isozymes, with the exception of the human A phenotype, does not differ between the two buffer systems. As previously observed, the relative electrophoretic mobility of the human $\mathrm{A}$ isozyme is altered in tricarboxylic acid buffer systems (Hopkinson et al., 1964). The dog and cow isozymes are better resolved, relative to the human B isozyme in the Tris-maleate buffer than in the Tris citrate buffer system but the relative pattern is maintained. With the exception of the cow-sheep pair (data not shown), all of the species exhibit electrophoretically unique isozymes. All of the small number of individuals examined, within each species, were homozygous at the ACP locus.

\section{Enzyme activity}

The differences in levels of acid phosphatase activity, expressed as units per $\mathrm{g}$ hemoglobin and assayed at saturating substrate concentrations, are fivefold between the two extreme species, dog and cow (Table 1). The levels of activity and the differences between the genotypes for the human isozymes are consistent with previous reports (Spencer et al., 1964; Eze et al., 1974; Yoshihara and Mohrenweiser, 1980). Sheep have a level of activity about $75 \%$ above the cow and similar to the activity in erythrocytes from the humans and chimp species. The activity in erythrocytes from the other primate species is one (baboon) and two (rhesus) times the human and chimpanzee activity.

Methanol is an effective phosphate acceptor (Tanizuki et al., 1977) and a 2.5-2.8-fold enhancement of activity is noted for all species when the assay is conducted in the presence of $10 \%$ methanol. As previously observed in studies of the isozymes from humans, only small differences in response are observed among the different isozymes.
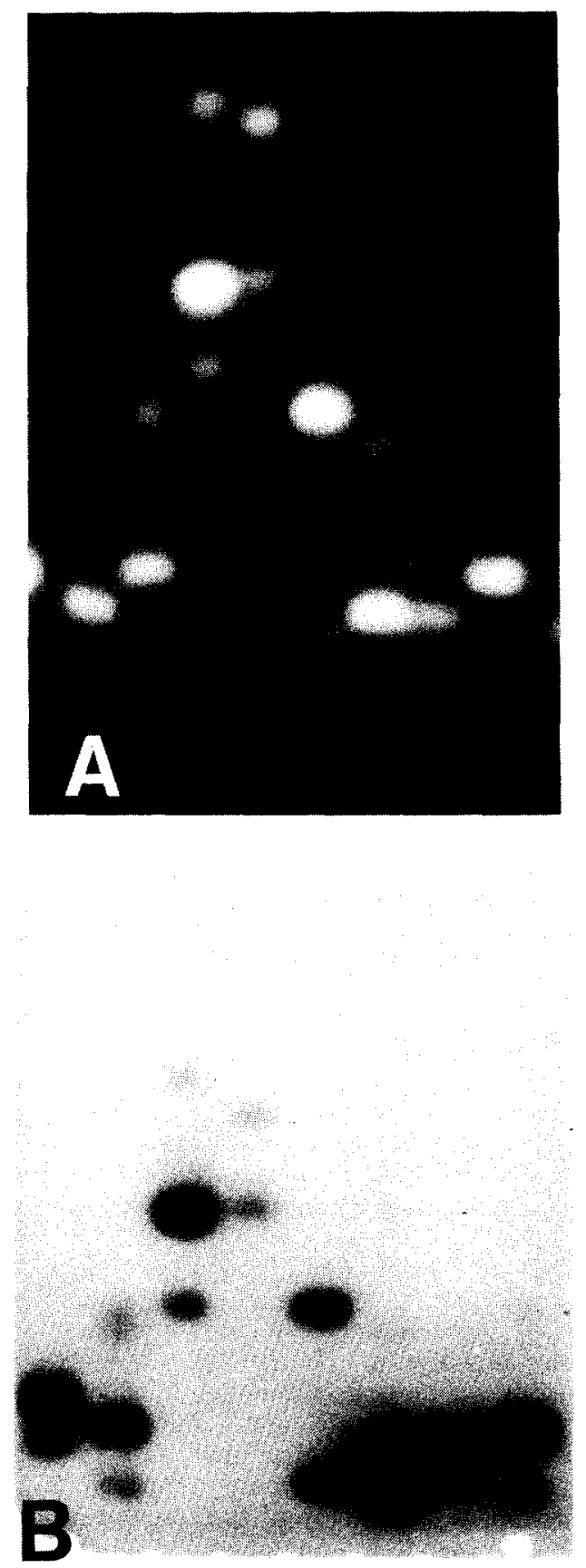

Fig. 1. Electrophoretic analysis of erythrocyte acid phosphatase from several species. Samples from the left are: (1) human A type (2) chimpanzee (3) rhesus (4) baboon (5) rabbit (6) dog (7) cow (8) human B type. The origin is at the bottom with the cathode to the top. Gel A Tris-malate-magnesium-EDTA buffer and stained with 4-methylumbelliferyl phosphate as substrate; gel B,

Tris-citrate buffer and stained with phenolpthalein. 
Table 1. Purine analog modulation of erythrocyte acid phosphatase from several species

\begin{tabular}{|c|c|c|c|c|c|c|c|c|c|c|c|}
\hline & \multirow[b]{2}{*}{ Activity } & \multicolumn{10}{|c|}{ Activity as $\%$ of Control } \\
\hline & & guanos ine & $6 M P^{b}$ & $\begin{array}{c}\text { hypo } \\
\text { xanthine }\end{array}$ & adenine & 6DMAP ${ }^{C}$ & $A P L^{d}$ & GEMP ${ }^{e}$ & $\mathrm{FA}^{\mathrm{f}}$ & DAP 9 & Rank $^{h}$ \\
\hline Chimp & 5.0 & 230 & 387 & 217 & 141 & 308 & 239 & 201 & 64 & 34 & $1.4 \pm 0.5$ \\
\hline Human $B$ & 5.4 & 217 & 366 & 208 & 140 & 315 & 229 & 196 & 65 & 38 & $1.9 \pm 0.9$ \\
\hline Human AB & $5 .+1$ & 253 & 363 & 206 & 168 & 362 & 220 & 217 & 56 & 37 & $2.9 \pm 0.9$ \\
\hline Human A & 4.1 & 268 & 344 & 190 & 182 & 380 & 212 & 228 & 53 & 42 & $5.4 \pm 1.7$ \\
\hline Rabb it & 11.6 & 304 & 357 & 203 & 185 & 420 & 207 & 245 & 48 & 39 & $6.0 \pm 1.3$ \\
\hline Dog & 18.0 & 321 & 353 & 201 & 192 & 410 & 223 & 253 & 47 & 41 & $6.2 \pm 1.7$ \\
\hline Sneep & 5.6 & 307 & 262 & 200 & 181 & 417 & 221 & 240 & 48 & 41 & $6.4 \pm 1.9$ \\
\hline Rhesus & 14.3 & 301 & 305 & 179 & 192 & 408 & 199 & 255 & 50 & 40 & $6.6 \pm 1.6$ \\
\hline Baboon & 9.1 & 314 & 302 & 175 & 202 & 443 & 201 & 258 & 45 & 41 & $8.3 \pm 0.9$ \\
\hline Cow & 3.2 & 364 & 269 & 168 & 238 & 461 & 186 & 276 & 36 & 51 & $9.9 \pm 0.3$ \\
\hline
\end{tabular}

$\mu \mathrm{mol}$ product/g hemoglobin.

b6-mercaptopurine; '6-dimethylaminopurine; dallopurinol; ${ }^{6}$ 6-ethylmercaptopurine; 'folic acid; ${ }^{\text {gdiaminopurine }}$

${ }^{h}$ Mean order $\pm S D$ for response to each of the purine analogs. The score is assigned as described in the text.

\section{Purine analog modulation}

The response of the erythrocyte enzyme from the eight species to modulation by various purine analogs is in Table 1. The genotype specificity of the human isozymes is similar to previous reports (Mansfield and Sensabaugh, 1978; Yoshihara and Mohrenweiser, 1980; Mohrenweiser and Novotny, 1982). Significant responses were observed for all the species examined indicating that the purine analog modulation is not a phenomenon restricted to ACP from human erythrocytes. Additionally, significant differences among species in the magnitude, but not in the direction, of the response are noted. The enzyme from bovine erythrocytes is at one extreme in responsiveness, being most responsive to guanosine, adenine, 6-dimethylaminopurine, 6-ethylmercaptopurine and folic acid (five of nine analogs). It is least responsive to hypoxanthine, allopurinol and diaminopurine (three of nine analogs). The enzyme from chimpanzee erythrocytes is at the opposite end of the spectrum from the bovine, being first or second least responsive to five modulators and first or second most responsive to the other four. In all cases, the response of the chimpanzee enzyme is very similar to the human B isozyme. The enzyme from the other primate (rhesus) and the sheep, dog and rabbit enzymes were consistently grouped between the human $\mathrm{A}$ isozyme and the baboon.

As a measure of consistency in response to modulation by this series of purine analogs, the relative position or order of the species for each compound was scored (Table 1). When this was done, the bovine and chimp were always at opposite extremes of responsiveness, in a manner similar to the human $B$ and $\mathrm{C}$ isozymes. The numerical scores were assigned, such that the bovine isozyme was arbitrarily assigned a higher score than the chimp isozyme. For example, the bovine isozyme was given a score of 10 for both guanosine (where it was the most responsive species) and 6-mercaptopurine (where it was the least responsive species) while the chimp at the other extreme in response was assigned scores of 2 and 1 respectively for these analogs. Thus, the score is not a numerical measure of the degree of response but rather an indication of the consistency of the order of response, relative to chimpanzee and bovine. As can be seen, although there is some overlap within the middle group (rabbit through rhesus) the consistency of the response for each species is similar to that observed for the genotypically different human isozymes

\section{Liver acid phosphatase}

The activity of the low molecular weight acid phosphatase isolated from bovine brain, human placenta and rat liver has been reported to be modulated by purine analogs (DiPietro and Zengerle, 1967; Tanizaki et al., 1977) and exhibit some of the responsiveness as is observed for the erythrocyte enzymes in Table 1. These include, for the bovine brain enzyme, guanosine, 6-mercaptoethylpurine and adenine activation (Tanizaki et al., 1977). Two significant differences are also observed, these being the absence of hypoxanthine activation of the bovine brain enzyme $(150 \%$ and $200 \%$ enhancement respectively for bovine and human erythrocytes) and the reported activation $(150 \%)$ by guanine, which inhibits the human erythrocyte ACP activity by $40 \%$ (Wurzinger et al., 1984). The response of partially purified ACP from erythrocytes and liver from human, bovine and rabbit to modulation by several purine analogs is in Table 2 . The enhancement of activity of the erythrocyte enzyme is very similar to that observed for the dialyzed, unfractionated erythrocyte enzyme (Table 1). In comparing the human erythrocyte ACP with the human liver low molecular weight ACP, 6-dimethylaminopurine and guanosine stimulate the liver isozyme more than the erythrocyte enzyme while greater stimulation of the erythrocyte enzyme is observed for 6-mercaptopurine and hypoxanthine. A similar dichotomy of enzymatic activity is observed with the rabbit erythrocyte and liver enzymes. Hypoxanthine and 6-mercaptopurine also enhance the activity of the bovine erythrocyte enzyme more than the liver enzyme as observed for the other species. In contrast to the results from other 
Table 2. Modulation of erythrocyte and liver low molecular weight acid phosphatase by several purine analogs

\begin{tabular}{|c|c|c|c|c|c|c|c|c|}
\hline & \multicolumn{8}{|c|}{ Activity as \% of Control } \\
\hline & \multicolumn{2}{|c|}{$60 M A P^{a}$} & \multicolumn{2}{|c|}{$6 M P^{b}$} & \multicolumn{2}{|c|}{ guanos ine } & \multicolumn{2}{|c|}{ nypoxanthine } \\
\hline & Liver & $\mathrm{RBC}$ & Liver & RBC & Liver & $\mathrm{RBC}$ & Liver & RBC \\
\hline Human & 411 & 365 & 236 & 335 & 307 & 248 & 147 & 179 \\
\hline Rabbit & 481 & 412 & 271 & 350 & 364 & 309 & 177 & 219 \\
\hline Bovine & 542 & 545 & 193 & 257 & 400 & 391 & 140 & 164 \\
\hline
\end{tabular}

"6-dimethylaminopurine

"6-mercaptopurine.

species though, the bovine liver and erythrocyte enzymes are stimulated equally by dimethylaminopurine and guanosine.

Electrophoretic analysis of the partially purified erythrocyte and liver enzymes indicate similar electrophoretic mobility profiles for the liver and the erythrocyte isozymes from each of the three species. There is no indication of additional isozymes in the liver preparations which are not present in both the fractionated and unfractionated erythrocyte samples using 4-methylumbelliferyl phosphate as the substrate. Also, no activity is observed in either the erythrocyte or liver preparation when the substrate for the tissue specific ACP isozymes, $a$-naphthyl phosphate, is used (data not shown).

\section{DISCUSSION}

The previous studies of the interaction between the genotypically different human ACP isozymes and different purine analogs indicate that the mechanism for modulation of activity involves significant structural specificity (Mansfield and Sensabaugh, 1975; Yoshahari and Mohrenweiser, 1980; Mohrenweiser and Novotny, 1982). Studies on the modulation of acid phosphatase activity by purine analogs have focused on the structural specificity of the purines, the majority of the data being from the human erythrocyte isozymes (Mansfield and Sensabaugh, 1978; Wurzinger et al., 1984). The role of the protein structure in regulating the magnitude of the response is expanded by this study of the erythrocyte enzyme from the seven species, in addition to the human isozymes. As seen in the study of the isozymes from the other species, the response of the most responsive isozyme is usually at least $50 \%$ greater than observed for the least responsive isozyme. More pertinent is the ordering of response which is observed. That is, the genotype specificity observed for the human isozymes, is also observed when the isozymes from other species are studied. This would suggest the enzyme has a single common binding site for the analogs studied and that all of the analogs modulate the enzymatic activity via a similar mechanism.

Modulation of the activity of a low molecular weight tissue acid phosphatase from human placenta (DiPietro and Zengerle, 1967) and bovine brain (Tanizaki et al., 1977) has been previously reported. The explanation for the differences in response to the several modulators between the bovine liver and erythrocyte enzyme preparations and those previously reported for the bovine brain (Tanizaki et al., 1977 ) is not clear. The increased activation of the liver preparations argues against a simple explanation involving an additional, unresponsive isozyme in the liver tissue. There are no indications of electrophoretic mobility differences between the erythrocyte and tissue enzyme preparation which would suggest that the two enzymes are products of different loci nor are additional bands of ACP activity observed for the preparation from any of the species. An enzyme with electrophoretic mobility characteristics similar to the erythrocyte enzyme has been previously observed in other human tissues (Sensabaugh, 1975; Swallow et al., 1973) although some evidence has also suggested some differences between the human erythrocyte enzyme and a low molecular weight ACP from liver (Taga et al., 1982). Additionally, two low molecular weight isozymes of ACP have recently been reported to exist in chicken muscle (Baxter and Suelter, 1984). The structural relationship between the erythrocyte ACP and the low molecular weight $\mathrm{ACP}(\mathrm{s})$ from tissue requires clarification.

The mechanism of the purine analog modulation of the activity of this small ( $\mathrm{MW}=12-14,000)$, monomeric enzyme (Fisher and Harris, 1971) has not been defined, although initial kinetic studies suggest an uncompetitive mechanism with the modulator binding at a site other than the substrate binding site (Mansfield and Sensabaugh, 1978). The enhancement of activity facilitates removal of the phosphate group from the phosphoenzyme intermediate but with a strong preference for $\mathrm{H}_{2} \mathrm{O}$ as the acceptor. That is, the modulator has only minimal effect on the transphosphorylation reaction with methanol as the phosphate acceptor (Wurzinger et al., 1984).

Human ACP genotypes (and therefore activity) have been associated with increased susceptibility to hemolytic anemia and jaundice and, as well, low birth weight and premature birth have been reported (Valentine et al., 1961; Bottini et al., 1971, 1972, 1976. 1980; Carapella et al., 1980). Erythrocyte ACP activity is inversely related to glutathione reductase activity and erythrocyte flavin adenine dinucleotide concentration (Mohrenweiser and Novotny, 1982). This is consistent with the proposed function of $\mathrm{ACP}$ as a flavin mononucleotide phosphatase (Mansfield and Sensabaugh, 1978) and could be the mechanism for the reported disease associations. A potential physiological role for purine analog modulation of ACP activity and/or any relationship to the disease associations is currently not obvious, though, given the nonphysiological concentrations of modulators required for significant in vitro modulation of activity. 
Further characterization of the enzyme from species exhibiting divergent responses to purine analog modulation of activity should provide insight into structural features of the enzyme which are involved in the modulation as any potential physiological significance of the purine effect.

Acknowledgements-Financial support was derived from the Department of Energy (EY-77-C-02-2828) (HWM) and a scholarship from the Government of India, Ministry of Education (JMN). The assistance and helpful discussions of K. H. Wurzinger are appreciated.

\section{REFERENCES}

Baldijao C. E. M., Guija E., Bittencourt H. M. S. and Chaimovich H. (1975) Steady state kinetics and the effect of SH inhibitors on acid phosphatase from bovine brain. Biochim. biophys. Acta 391, 316-325.

Baxter J. H. and Suelter C. H. (1984) Purification and partial characterization of the low molecular weight acid phosphatase from avian pectoral muscle. Fedn proc. Fedn Am. Socs exp. Biol. 43, 1548 (abs)

Bottini E., Lucarelli P., Agostino R., Palmarino R., Businco L. and Antognori G. (1971) Favism: association with erythrocyte acid phosphatase phenotype. Science 171, 409.

Bottini E., Lucarelli P., Bastianon V. and Gloria F. (1972) Erythrocyte acid phosphatase polymorphism and haemolysis. J. med. Genet. 9, 434-435.

Bottini E., Scacchi R., Gloria-Bottini F., Mortera J., Palmarino R., Carapella-deLuca E., Lapi A. S. and Noclari D. (1976) Nconatal jaundice and erythrocyte acid phosphatase phenotype. Lancet 1, 918.

Bottini E., Carapella E., Orzalesi M., Lucarelli P., Pascone R., Gloria-Bottini F. and Coccia M. (1980) Is there a role of erythrocyte acid phosphatase polymorphism in intrauterine development. Am. J. Hum. Genet. 32, 764-767.

Carapella E., Pascone R., Gori M. G., Matteucci P., Gloria-Bottini F., Morthera J., Lucarelli P., Scacchi R. and Bottini E. (1980) The genetic component of quantitative perinatal variables. An analysis of relations between erythrocyte acid phosphatase phenotype and birth weight, gestational age and serum bilirubin level in the first days of life. J. Perinat. Med. 8, 42-47.

Chaimovich H. and Nome F. (1970) Purification and properties of acid phosphatase from bovine brain. Archs Biochem. Biophys. 139, 9-16.

DiPietro D. L. and Zengerle F. S. (1967) Separation and properties of three acid phosphatases from human placenta. J. biol. Chem. 243. 339l-3396.

Fielek S. and Mohrenweiser H. W. (1979) Erythrocyte enzyme deficiencies assessed with a miniature centrifugal analyzer. Clin. Chem. 25, 384-388.

Fisher R. A. and Harris H. (1971) Further studies of the molecular size of red cell acid phosphatase. Ann. Hum. Genet. 34, 449-453.

Hopkinson D. A., Spencer N. and Harris H. (1964) Genetic studies on human red cell acid phosphatase. Ann. Hum. Genet. 16, 141-154.
Lawrence G. L. and VanEtten R. L. (1981) The lowmolecular-weight acid phosphatase from bovine liver: isolation, amino acid composition, and chemical modification studies. Archs Biochem. Biophys. 206, $122-131$.

Luffman J. E. and Harris H. (1967) A comparison of some properties of human red cell acid phosphatase of different phenotypes. Ann. Hum. Genet. 30, 387-401.

Mansfield E. and Sensabaugh G. F. (1977) Phenotypic differences in purine modulation of erythrocyte acid phosphatase activity. Lancet 2, 201-202.

Mansfield E. and Sensabaugh G. F. (1978) Red cell acid phosphatase: modulation of activity by purines. In The Red Cell (Brewer G. J., ed.), pp. 233-247. Alan R. Liss, New York.

Mohrenweiser H. W. and Novotny J. E. (1982) ACP GLA-1 a low-activity variant of human erythrocyte acid phosphatase: association with increased glutathione reductase activity. Am. J. Hum. Genet. 34, 425-433.

Neel J. V., Mohrenweiser H. W. and Meisler M. M. (1975) Rate of spontaneous mutation at human loci encoding protein structure. Proc. natn. Acad. Sci. USA 77, 6037-6041.

Rehkop D. M. and VanEtten, R. L. (1975) Human liver acid phosphatases. Hoppe-Zeyler's Z. Physiol Chem. 356, 1775-1782.

Saini M. S. and VanEtten R. L. (1978) A homogeneous isozyme of human liver acid phosphatase. Archs Biochem. Biophys. 191, 613-624.

Saini M. S., Buchwald S. L., Van Etten R. L. and Knowles J. R. (1981) Stereochemistry of phospho transfer catalyzed by bovine liver acid phosphatase. Proc. natn. Acad. Sci. USA 256, 10453-10455.

Sensabaugh G. F. (1975) Genetic and nongenetic variation of human acid phosphatases. In Isozymes I: Molecular Structure (Markert C. L., ed.), pp. 367-380. Academic Press, New York.

Sensabaugh G. F. and Golden V. L. (1978) Phenotype dependence in the inhibition of red cell acid phosphatase (ACP) by folates. Am. J. Hum. Genet. 30, 553-560.

Swallow D. M., Povey S. and Harris H. (1973) Activity of the "red cell" acid phosphatase locus on other tissues. Ann. Hum. Genet. 37, 31-38.

Taga E. M. and VanEtten R. L. (1982) Human liver acid phosphatase: purification and properties of a lowmolecular-weight isoenzyme. Archs Biochem. Biophys. 214, 505-515.

Tanizaki M. A., Bittencourt H. M. S. and Chaimovich H. (1977) Activation of low molecular weight acid phosphatase from bovine brain by purines and glycerol. Biochim. biophys. Acta 485, 116-123.

Turner T. R., Wade P. T. and Mohrenweiser H. W. (1984) Variation in erythrocyte enzyme activity among primate species. Comp. Biochem. Physiol. 77B, 541-545.

Valentine W. N., Tanaka R. R. and Fredricks R. E. (1961) Erythrocyte acid phosphatase in health and disease. $\mathrm{Am}$. J. Clin. Path. 36, 328-332.

Wurzinger K. H., Novotny J. E. and Mohrenweiser H. W. Structural features of purine analogs associated with modulation of human erythrocyte acid phosphatase activity. Molec. Cell. Biochem. (in press).

Yoshihara C. M. and Mohrenweiser H. W. (1980) Characterization of $\mathrm{ACP}_{\mathrm{I}^{\prime}}^{\mathrm{TIC}-1}$, an electrophoretic variant of erythrocyte acid phosphatase restricted to the Ticuna Indians of Central Amazonas. Am. I. Hum. Genet. 32, 898-907. 